\title{
Cultural influence on the adoption of social media platforms by employees
}

Sikedi Ramawela

Joshua Ebere Chukwuere

North-West University, South Africa

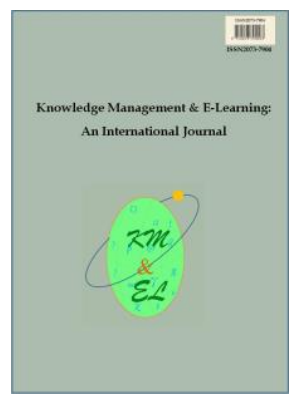

Knowledge Management \& E-Learning: An International Journal (KM\&EL) ISSN 2073-7904

Recommended citation:

Ramawela, S., \& Chukwuere, J. E. (2020). Cultural influence on the adoption of social media platforms by employees. Knowledge Management \& E-Learning, 12(3), 344-358. https://doi.org/10.34105/j.kmel.2020.12.018 


\title{
Cultural influence on the adoption of social media platforms by employees
}

\section{Sikedi Ramawela}

Department of Information Systems

North-West University, South Africa

E-mail: ramawelasikedi@gmail.com

\section{Joshua Ebere Chukwuere*}

Department of Information Systems

North-West University, South Africa

E-mail: joshchukwuere@gmail.com

*Corresponding author

\begin{abstract}
The growth of technology has impacted billions of lives by allowing people to connect with others through social media platforms such as Facebook, Twitter, Skype, WhatsApp, and so on. Despite the advantages of technology, there has been notable resistance from employees, especially the older generations, who are not eager to adopt social media technologies into their everyday lives. The purpose of this research was to investigate the influence of culture in the adoption of social media by employees in Mafikeng. A questionnaire was utilized to collect data from 252 employees across various government and non-government departments around the Mafikeng business area. The findings revealed the cultural factors that influence employees' adoption of social media platforms, employees' readiness to adopt social media, and the impacts of culture on social media adoption by employees.
\end{abstract}

Keywords: Culture; Employees; Social media; Social media platforms; Technology

Biographical notes: Sikedi Ramawela was an Hons student in the Department of Information Systems, Faculty of Economic and Management Sciences, North-West University (NWU), South Africa. Her research areas include smartphones, social media, and many more.

Prof. Joshua Chukwuere is an Associate Professor of information systems, North-West University (NWU), South Africa. He is also a consultant in the field of digital transformation and social media. His research area includes digital transformation, social media, mobile security, e-learning, smart city, ehealth, Internet of things, and many more. He has published several accredited journals and conference papers and has presented papers at a national and international conference. 


\section{Introduction}

Social media platforms have revolutionized the world of communication and dissemination of information (Kumar \& Dinakaran, 2019). The use of various kinds of technology in recent years has had a significant impact on humans, personally and socially, particularly in developing countries. The innovation of cutting-edge technology does not solely depend on the market and economic advancement. However, there are other contributing factors, such as culture, that define the belief system of the users. Culture is one of the important contributing factors that give way to new ideas and innovations (Lekhanya, 2013; Gökçe \& Dogerlioglu, 2019).

The concept of social media is described as a network that is composed of individuals or organizations that have the same interests, inspirations, qualities, and objectives (Pereira, Pereira, \& Pinto, 2011). Internet and social media have facilitated accessible communication in making life easier for many, including employees, because they can communicate with people who have mutual interests, share the same knowledge, connect with family members, colleagues, and discuss work-related issues, amongst other benefits. The provision of easy connection makes social media a vital part of human life. However, employees' ability to adopt these social media platforms are directly and indirectly influenced by their culture and other personal factors.

Despite all the advantages associated with social media platforms, the most notable point remains that there are fears of adopting technology by the working class (employees), specifically the older generation. The adoption of technology is influenced by the users' culture (Malik, Nawaz, Shujahat, Kianto, Hussain, \& Ali, 2019; Chukwuere, Mavetera, \& Mnkandla, 2017; Joshua, Nehemiah, \& Ernest, 2015; Lekhanya, 2013). Various elements contribute to senior citizens' acceptance of these technologies; amongst them are cultural factors such as being Africanised in beliefs and values, as well as having a different perspective about life and others. Based on the information above, this study explored the impacts of culture on employees' adoption of social media in their daily life activities and events. The study further aimed to understand those factors, particularly employee culture, in examining whether it contributes toward the adoption of social media platforms. Furthermore, this study determined the employees' readiness to adopt social media and understand its cultural impacts. The research questions for the study were:

1. What are the cultural factors that influence employees' adoption of social media platforms?

2. What is the level of employees' readiness in the adoption of social media?

3. What are the impacts of culture on social media adoption?

\section{Problem statement and objectives of the study}

Nowadays, many organizations are adopting social networking platforms to improve their sustainability, to remain competitive in the corporate world, and to improve communication with their employees (Singla \& Durga, 2015). Social media platforms improve communication and access to pieces of information (Kumar \& Dinakaran, 2019). According to Haddud, Dugger, and Gill (2016), social media applications provide opportunities for organizations to engage with their employees to communicate and share personal and work-related information with each other. Besides, Abubakar, Patricia, Samuel, and Totolo (2017) believe that organizations in developing nations are yet to embrace the adoption of social media when compared to developed countries. 
Not minding the adaptations, most of the employees who prefer doing things traditionally may view social media as a threat that challenges their beliefs, values, and their personal and social lives (Vithayathil, Dadgar, \& Osiri, 2020). The researchers' further support the view of Reneau (2013), who suggested that the older generations are moving at a slower pace in accepting and integrating communication technologies into their livelihood. Based on the literature, it has been realized that most employees have not adopted the idea of using social media platforms to advance their personal and corporate lives because they are not fascinated with it or may find it challenging to adopt. The literature also shows that culture influence employees in accepting some social media applications (Lekhanya, 2013). So far, little is known empirically of the influence of culture on employees adopting social media, specifically in Mahikeng, the capital city of the North-West Province of South Africa, which is still commonly known as Mafikeng and previously Mafeking. Therefore, the primary aim of this research was to determine the impacts of culture on employees utilizing social media.

\section{Literature review}

\subsection{Social media}

The advent of social media can be traced back to the year 2000. However, it was only in the year 2000 that social media came to life and became a concrete concept with mature features and advancements (Edosomwan, Prakasan, Kouame, Watson, \& Seymour, 2011). Social media is an Internet-based platform that allows multiple users to communicate and share information and content (Singh \& Sinha, 2017; Parveen et al., 2015). Boyd and Ellison (2008) defined social networking sites as web-based services that enable the construction of a public profile within a bounded system, allowing individuals to get connected with others, sharing a common interest or viewing within and outside the network. Leonardi, Huysman, and Steinfield (2013) further described social media as a means of communicating with external parties using various platforms such as Facebook, Myspace, Twitter, and many others.

Kaitlin (2010) adds that social media sites establish modern ways of social interaction and building friendships. The research further emphasizes the argument that social networking technologies should be designed in such a way that they support people's culture, values, and beliefs (Lekhanya, 2013; Ractham \& Srisamran, 2018). This support is essential in developing countries.

\subsection{Social media adoption in South Africa}

South Africa has the highest rate of users engaging in mobile technology and mobile social media on the African continent (Beger \& Sinha, 2012). According to Shezi (2017), there is an increased number of households connecting to the Internet, with $48.7 \%$ in 2014 to $53.3 \%$ in 2015 in South Africa. Besides, the principal place where people access the Internet is mainly at their workplaces, households, and schools (Mzekandaba, 2016; Jami Pour, Matin, Yazdani, \& Kouchak Zadeh, 2019; Panjaburee \& Srisawasdi, 2018). Shezi (2016) further states that over 13 million users make use of social media platforms in South Africa; about 10 million users access social media platforms solely using mobile devices. Literature indicates that South Africa's general public has embraced social media platforms in different aspects of their lives and activities. However, little is empirically known of the impact of culture on employees adopting this platform. 


\subsection{The impact of culture on social media}

Culture is an essential element when developing technological artefacts, because users want to know the contributing factors that affect their behaviour, thinking, and feeling when accepting these technologies (Pineda, 2014; Chukwuere et al., 2017; Joshua et al., 2015; Chukwuere, Mavetera, \& Mnkandla, 2016). Lekhanya (2013) further adds that culture contributes to the establishment of technological advancements and innovative ideas. Culture is a complicated and complete set of identity that comprises of information, belief, skills, ethics, law, custom, and other abilities, routine, and patterns gained by an individual as a member of the society (Spencer-Oatey, 2012). Waters and Lo (2012) defined culture as something that changes over time; it has been mastered and preserved, then passed from one generation to another with an everyday interaction. In this study, culture is understood as the attitude, behaviour, and acceptance of social media by users in developing countries.

\subsection{The implication of culture in adoption of social media}

A study conducted in the United States and Korea suggests that people are influenced by culture when adopting social media technologies; as such, these technologies should be developed in such a way that they can accommodate users' cultural differences (Kim, Sohn, \& Choi, 2011). According to Andzulis, Panagopoulos, and Rapp (2012) and Pimmer, Lee, and Mwaikambo (2018), social media is something that keeps evolving and can be adopted in ways such that it does not disturb the organizational culture. Despite all the studies conducted about social media, there is still limited research that concludes on the reasons for and adoption of social media (Boyd \& Ellison, 2008).

\section{Research method}

This study followed a quantitative research methodology. Quantitative research can be described as an instrument used to collect data in numerical form, which is examined using mathematical formula (Muijs, 2010). Walliman (2017) further emphasizes that this type of research deals with analyzing data by making use of numbers and numerical procedures to find results. Different kinds of philosophies can be used in research, namely positivism, relativism, postmodernism, and critical realism. This study followed the ideals in the positivism philosophy. The positivism approach involves accepting that the world is real and finding out more about reality (Walliman, 2017).

By applying the positivist philosophical approach in this study, it assisted the researchers in determining whether or not there are cultural impacts on the decision of employees in adopting social media platforms. The researchers collected data from respondents using a questionnaire survey. A random sampling method was used to gather enough data from a large employee population. A total of 260 questionnaires was distributed, and 252 were returned, which is a $97 \%$ return rate. 


\section{Results and discussions}

\subsection{Demographics of participants}

The demographic questions in the survey were aimed at presenting the personal details of the participants, such as their gender, age, status, educational level, and others, as shown in Table 1.

Table 1

Demographic information

\begin{tabular}{|c|c|c|c|c|}
\hline & Questions & Options & Frequency & Percentage \\
\hline \multirow[t]{5}{*}{1} & Your status? & $\mathrm{Mr}$ & 99 & 39.3 \\
\hline & & Mrs & 43 & 17.1 \\
\hline & & Miss & 101 & 40.1 \\
\hline & & Dr & 7 & 2.8 \\
\hline & & Professor & 2 & 0.8 \\
\hline \multirow[t]{2}{*}{2} & Your gender? & Male & 110 & 43.65 \\
\hline & & Female & 142 & 56.35 \\
\hline \multirow[t]{11}{*}{3} & Your home language? & Afrikaans & 13 & 5.2 \\
\hline & & English & 13 & 5.2 \\
\hline & & IsiNdebele & 9 & 3.6 \\
\hline & & IsiXhosa & 22 & 8.9 \\
\hline & & IsiZulu & 19 & 7.5 \\
\hline & & SiSwati & 10 & 4 \\
\hline & & Southern Sotho & 16 & 6.3 \\
\hline & & Setswana & 115 & 45.6 \\
\hline & & Northern Sotho & 19 & 7.5 \\
\hline & & Tshivenda & 8 & 3.2 \\
\hline & & Xitsonga & 8 & 3.2 \\
\hline \multirow[t]{6}{*}{4} & Your age groups? & 25-younger & 53 & 21 \\
\hline & & $26-31$ & 49 & 19.4 \\
\hline & & $32-37$ & 55 & 21.8 \\
\hline & & $38-43$ & 39 & 15.5 \\
\hline & & $44-49$ & 25 & 9.9 \\
\hline & & 50-older & 31 & 12.3 \\
\hline \multirow[t]{4}{*}{5} & Your race? & Black & 227 & 90.1 \\
\hline & & White & 19 & 7.5 \\
\hline & & Coloured & 5 & 2.0 \\
\hline & & Indian/Asian & 1 & 0.4 \\
\hline \multirow[t]{3}{*}{6} & Your education levels? & Higher and university & 186 & 73.8 \\
\hline & & Secondary & 60 & 23.4 \\
\hline & & Primary & 6 & 2.4 \\
\hline
\end{tabular}


The results show that 252 respondents from different government and nongovernment departments around Mahikeng participated in completing the questionnaire. As shown in Table 1, 39.3\% (99) of the respondents were Mr, 40.1\% (101) Miss, and many more. A total of $43.65 \%$ (110) of the participants are male, while $53.65 \%$ (142) are female. The findings suggest that more females participated in the study.

Concerning the home language of the participants, $8.7 \%$ (22) speak isiXhosa, $7.5 \%$ (19) speak isiZulu, $45.6 \%$ (115) speak Setswana, and others. The result shows that the majority of the participants spoke Setswana as Mahikeng is located in a geographical area dominated by Setswana speakers. The findings also show that $21.0 \%$ (53) aged 25 and younger, $19.4 \%$ (49) were 26 to 31 years old, and $21.8 \%$ (55) were 32 to 37 years old, among others.

Furthermore, $90.08 \%$ (228) of the participants are blacks with African culture, and $7.54 \%$ (19) are whites, among others. The study shows that majority of the participants are blacks. Finally, 73.8\% (186) of the participants had a higher degree and university educational qualification, and $23.4 \%$ (60) had a secondary qualification, among others.

\subsection{What are the cultural factors that influence employees' adoptions of social media platforms?}

The first objective of the study was to understand the different cultural factors that impact employees' attitudes towards the adoption of social media platforms. Six questions in the survey were used to achieve this research objective.

\subsubsection{Culture as an influence on the adoption of social media}

According to the study, $32.5 \%$ (82) consider their culture when adopting social media. A survey conducted in the United States of America (USA) and Korea revealed that culture influences people when they utilize social media and other emerging technologies (Kim et al., 2011). Also, Pineda (2014) stated that culture is a crucial element to consider when developing technological artefacts because people want to know its effects on their behaviour, thinking patterns, and feelings when accepting these technologies. 39.3\% (99) do not consider their culture when adopting social media. While $28.2 \%$ (71) are uncertain as to whether or not their culture influences their adoption of social media platforms. Therefore, the findings indicate that most participants $(39.3 \%)$ do not consider their culture as an influencing factor in the adoption of social media.

\subsubsection{The effect of culture in the adoption of social media}

The study highlights that $39.7 \%$ (100) indicated that culture does affect their adoption of social media. $45.2 \%$ (114) stated that culture does not affect them, while $15.1 \%$ (38) of the participants are uncertain whether culture affects employees in adopting social media. Overall, the results show that employees are not influenced by culture in their adoption of social media.

\subsubsection{Attitude towards culture}

The study's findings highlight that $38.9 \%$ (98) perceive their culture as very important to them when adopting social media and $54.4 \%$ (137) as necessary. The study further shows 
that $5.2 \%$ (13) suggested that employee's attitude towards culture is less critical in adopting social media, while $1.6 \%$ (4) believe that their attitude towards culture is not essential when adopting social media. The outcome shows that participants value their culture greatly in the adoption of social media.

\subsubsection{Respect culture in the use of social media}

The findings showed that $81.0 \%$ (204) of the respondents respect their culture; 8.7\% (22) indicated that they do not respect their culture. The study further found that 9.9\% (25) are uncertain whether employees respect their culture when using social media. It is proven from this result that participants respect and regard their culture when considering and using social media platforms. It shows that culture plays a significant role in employee's (users') attitude on social media.

\subsubsection{Consideration of culture as more important than using social media}

The study found that $70.6 \%$ (178) of the participants considered their culture as more important than using social media, followed by $17.9 \%$ (45), who suggested that culture was not an important variable in their use of social media, while $11.5 \%$ (29) were uncertain. From the findings, participants would prefer to maintain their cultural values rather than using SM platforms.

Table 2

Cultural factors affecting the adoption of social media

\begin{tabular}{llll}
\hline & Options & Frequency & Percent \\
\hline 1 & Language & 30 & 11.9 \\
2 & Belief & 24 & 9.5 \\
3 & Religion & 21 & 8.3 \\
4 & Customs and traditions & 39 & 15.5 \\
5 & Symbols & 20 & 7.9 \\
6 & Communication & 25 & 9.9 \\
7 & Arts and literature & 18 & 7.1 \\
8 & None of the above & 75 & 29.8 \\
& Total & 252 & 100.0 \\
\hline
\end{tabular}

As shown in Table 2,15.5\% (39) of the participants believed that their customs and traditions are the fundamental cultural factors that impact on employees' usage of SM, while $29.8 \%$ (75) said none of the above-mentioned cultural factors affect them. The results show that different cultural factors affect employees in developing countries in their usage of SM.

\subsection{What is the level of employees' readiness in the adoption of social media?}

This second research objective of the study was to determine whether the employees in Mafikeng were ready and willing to use social media. About twelve (12) questions in the survey were used to achieve the objective. 


\subsubsection{Use of social media}

The findings indicate that $91.3 \%$ (230) of the respondents use SM, 7.1\% (18) are not using social media, $1.2 \%$ (3) are uncertain of their use of social media, while $0.4 \%$ (1) were wrongly captured. The results show that employees who participated in the study have adopted the use of SM for different activities.

Table 3

Places of social media access

\begin{tabular}{llll}
\hline & Options & Frequency & Percent \\
\hline 1 & Home & 148 & 58.7 \\
2 & Workplace & 68 & 27.0 \\
3 & Internet café & 13 & 5.2 \\
4 & Shopping mall & 7 & 2.8 \\
& Total & 236 & 93.7 \\
\hline
\end{tabular}

As shown in Table 3, 58.7\% (148) of the participants accessed social media at home. The findings relate to Shezi's (2016) study, which indicates an increase in South African households' Internet usage. Furthermore, $27.0 \%$ (68) access social media at their workplace. Mzekandaba's (2017) study found that the workplace is one of the leading places where people have access to the Internet. Mzekandaba (2017) suggests that workplaces, households, and schools are the primary places where people access the Internet. The results clearly show that most of the employees (participants) access social media at home, which can be attributed to the high penetration of Internet connectivity in their homes.

Table 4

Frequent use of social media

\begin{tabular}{llll}
\hline & Options & Frequency & Percent \\
\hline 1 & Daily & 192 & 76.2 \\
2 & Weekly & 31 & 12.3 \\
3 & Twice a month & 8 & 3.2 \\
4 & Monthly & 4 & 1.6 \\
& Total & 235 & 93.3 \\
\hline
\end{tabular}

Table 4 shows that indicates that $76.2 \%$ (192) of the participants used social media daily. Furthermore, the study revealed that $61 \%$ (154) of the respondents used their SM on their smartphones. This finding is supported by Shezi's (2016) findings, which suggests that millions of users in South Africa access social media platforms exclusively through their mobile phones. Additionally, Cilliers, Chinyamurindi, and Viljoen (2017) stated that nearly 30 million South Africans use mobile phones to connect to social media.

As shown in Table 5, about $21.8 \%$ (55) of the participants spend five hours and more daily on their social media platforms. The results show that most employees spend more than five hours on SM platforms daily. The study further suggests that employees spend most of their time daily on WhatsApp $(33.3 \%, 84)$, Facebook $(29.8 \%, 75)$, Twitter $(9.5 \%, 24)$, Imo $(9.1 \%, 23)$, and others. This study's findings indicate that employees spend most of their time on WhatsApp. The statistics' findings are contrary to Fin24 
(2017) that suggests that Facebook is the most popular social media site, with a $29 \%$ population in South Africa.

Table 5

Daily time spent on social media

\begin{tabular}{llll}
\hline & Options & Frequency & Percent \\
\hline 1 & Less than 30 minutes & 24 & 9.5 \\
2 & 30 minutes to 1 hour & 35 & 13.9 \\
3 & $1-2$ hours & 26 & 10.3 \\
4 & $2-3$ hours & 23 & 9.1 \\
5 & $3-4$ hours & 47 & 18.7 \\
6 & $4-5$ hours & 26 & 10.3 \\
7 & 5 hours and longer & 55 & 21.8 \\
& Total & 236 & 93.7 \\
\hline
\end{tabular}

Table 6

Factors that contribute towards employees' readiness to adopt SM

\begin{tabular}{|c|c|c|c|c|}
\hline & Questions & Options & Frequency & Percentage \\
\hline \multirow[t]{3}{*}{1} & $\begin{array}{l}\text { Am ready to use social media } \\
\text { because it contributes to my } \\
\text { personal quality of life? }\end{array}$ & Strongly agree & 169 & 69.06 \\
\hline & & Neutral & 54 & 21.4 \\
\hline & & Strongly disagree & 23 & 9.12 \\
\hline \multirow[t]{3}{*}{2} & Am ready to adopt social media & Strongly agree & 190 & 75.39 \\
\hline & & Neutral & 42 & 16.7 \\
\hline & & Strongly disagree & 14 & 5.6 \\
\hline \multirow[t]{3}{*}{3} & $\begin{array}{l}\text { Social media provides more } \\
\text { freedom of communication? }\end{array}$ & Strongly agree & 190 & 75.39 \\
\hline & & Neutral & 47 & 18.7 \\
\hline & & Strongly disagree & 9 & 3.57 \\
\hline \multirow[t]{3}{*}{4} & Am ready to use social media due & Strongly agree & 201 & 79.76 \\
\hline & & Neutral & 35 & 13.9 \\
\hline & & Strongly disagree & 10 & 8.0 \\
\hline \multirow[t]{3}{*}{5} & Am ready to adopt social media due & Strongly agree & 190 & 75.39 \\
\hline & & Neutral & 42 & 16.7 \\
\hline & & Strongly disagree & 14 & 5.6 \\
\hline 6 & Am ready to adopt social media & Strongly agree & 206 & 81.74 \\
\hline
\end{tabular}

because it allows easier communication with friends, families and colleagues always? 

enhance productivity at the workplace?

8 Am ready to adopt social media for personal purposes?

Strongly disagree

\begin{tabular}{rrr} 
Neutral & 82 & 32.5 \\
Strongly disagree & 25 & 9.9 \\
Strongly agree & 184 & 73.0 \\
& & \\
Neutral & 50 & 19.8 \\
Strongly disagree & 12 & 4.76 \\
Strongly agree & 108 & 42.85 \\
& & \\
Neutral & 104 & 41.3 \\
Strongly disagree & 34 & 13.49 \\
\hline
\end{tabular}

Table 6 provides an analysis of the factors that contribute to employees' adoption of SM. The first question proves that SM adds to employees' personal lives. The second question shows that SM promotes intercultural attribute sharing. The third question suggests that it provides borderless freedom in communication, both personal and at work. The fourth question also indicates that employees are ready to adopt SM because it allows for unlimited access to current and trending news and information, 24/7. Furthermore, the fifth question suggests that employees are prepared to adopt SM due to its ease to use, while the sixth question illustrates that employees are ready to adopt SM because it provides easy and accessible communication with friends, families, and colleagues. These findings are the fundamental factors that contribute to employees adopting social media in developing countries.

\subsection{What are the impacts of culture on social media adoption?}

As a third research objective, the study aimed to determine further the influence that culture has on social media. This objective was addressed by nine questions to establish the impacts of culture on social media.

The results presented in Table 7 show that $50.39 \%$ (127) suggests that culture has an impact on their social media usage. The findings also proved that $36.11 \%$ (91) of the respondents believe that culture does not destroy social media.

In addition, $48.4 \%$ (122) of the employees were neutral on whether cultural beliefs impact positively on the usage of social media. Furthermore, 50\% (126) of the respondents were indifferent as to whether or not cultural beliefs affect the usage of social media negatively, as seen in question 4 . The findings mean that respondents are not sure whether cultural beliefs impact positively or negatively on employees' adoption of social media platforms.

The findings show that $46.4 \%$ (117) of the respondents are impacted by their culture, while posting, sharing post/s (information) and commenting on social media. The findings indicate that culture impacts on the users' attitude towards post/s, comments, and contents on social media. In question $6,33.3 \%$ (84) of the participants are of the opinion that culture is not considered while designing social media platforms. The findings prove 
the lack of users' cultural consideration in the design and development of social media platforms.

Table 7

Cultural impact on social media usage

\begin{tabular}{|c|c|c|c|c|}
\hline & Questions & Options & Frequency & Percentage \\
\hline \multirow[t]{3}{*}{1} & $\begin{array}{r}\text { Does your culture have impact on } \\
\text { social media usage? }\end{array}$ & Strongly agree & 127 & 50.39 \\
\hline & & Neutral & 74 & 29.4 \\
\hline & & Strongly disagree & 47 & 18.65 \\
\hline \multirow[t]{3}{*}{2} & $\begin{array}{r}\text { Do you think culture destroys } \\
\text { social media usage? }\end{array}$ & Strongly agree & 79 & 31.34 \\
\hline & & Neutral & 77 & 30.6 \\
\hline & & Strongly disagree & 91 & 36.11 \\
\hline \multirow[t]{3}{*}{3} & $\begin{array}{r}\text { Cultural beliefs impact positively } \\
\text { on social media usage? }\end{array}$ & Strongly agree & 92 & 36.50 \\
\hline & & Neutral & 122 & 48.4 \\
\hline & & Strongly disagree & 33 & 13.09 \\
\hline \multirow[t]{3}{*}{4} & $\begin{array}{l}\text { Do cultural beliefs negatively } \\
\text { impact social media usage? }\end{array}$ & Strongly agree & 63 & 25 \\
\hline & & Neutral & 126 & 50 \\
\hline & & Strongly disagree & 58 & 23.1 \\
\hline \multirow[t]{3}{*}{5} & Culture influences posting, sharing & Strongly agree & 117 & 46.4 \\
\hline & & Neutral & 74 & 29.4 \\
\hline & & Strongly disagree & 57 & 22.6 \\
\hline \multirow[t]{3}{*}{6} & Do you think cultural factors are & Strongly agree & 82 & 32.5 \\
\hline & & Neutral & 82 & 32.5 \\
\hline & & Strongly disagree & 84 & 33.3 \\
\hline \multirow[t]{3}{*}{7} & Social media is not suitable for & Strongly agree & 77 & 30.6 \\
\hline & & Neutral & 104 & 41.3 \\
\hline & & Strongly disagree & 66 & 26.2 \\
\hline \multirow[t]{3}{*}{8} & My culture encourages the adoption & Strongly agree & 77 & 30.6 \\
\hline & & Neutral & 84 & 33.3 \\
\hline & & Strongly disagree & 87 & 32.5 \\
\hline \multirow[t]{3}{*}{9} & I think social media is promoting & Strongly agree & 127 & 50.4 \\
\hline & & Neutral & 92 & 36.5 \\
\hline & & Strongly disagree & 29 & 11.5 \\
\hline
\end{tabular}


The results also show that $41.3 \%$ (104) are neutral (not sure) as to whether social media is not suitable to support the cultural belief system of the employees (users), while, $32.5 \%$ (87) strongly disagreed that their culture encourages them to adopt social media, as noted in question 8. In the last issue (question 9), the study found that $50.4 \%$ (127) of the respondents strongly agree that social media platforms promote foreign culture and its values in the society.

In summary, the results of the study indicate that culture impacts on individuals using different social media platforms, and it does not destroy or discourage the usage; the positive and negative impacts of culture on social media platforms cannot be proven. However, culture regulates what and how people (employees) express themselves, post comments, and share information on social media. The study also demonstrates that users' culture is not considered in the design and implementation of social media platforms by designers. Furthermore, it was noted that culture does not encourage users (employees) to adopt any social media platform. Importantly, social media platforms promote the sharing of cultures and values between individuals, as well as across societies and nations.

\section{Discussions}

The results in Table 1 shows that $40.1 \%$ of the respondents are Miss, while $39.3 \%$ are $\mathrm{Mr}$. The gender indicates that $56.35 \%$ of the contributors are Female, while $43.65 \%$ are Male. On the home language, the majority of the respondents speak Setswana (45.6\%), and the rest follows. On the age group, more participant's age was between 32 to 37 years, accounting for $21.8 \%$. The result further shows that $90.1 \%$ of the respondents were blacks, and $73.8 \%$ of them have a higher degree.

\subsection{What are the cultural factors that influence employees' adoption of social media platforms?}

The findings indicate that most participants do not consider their culture as an influencing factor in the adoption of social media; however, research findings by Lekhanya (2013) and Pimmer, Lee, and Mwaikambo (2018) found that culture is the contributing factor that gives way for the establishment of technological advancements and innovative ideas. The overall research results show that employees are not affected by the culture in their adoption of social media. The research findings show that participants value their culture greatly in the adoption of social media.

It is proven from the results that participants respect and regard their culture when considering and using social media platforms. It shows that culture plays a vital role in users' attitudes regarding SM. The findings are supported by Lekhanya (2013), Pineda (2014), and Chukwuere et al. (2017), who believe that culture is one of the important contributing factors in technology adoption. Based on the findings, participants would prefer to maintain their cultural value, rather than using SM platforms. It indicates that respondents do not want to lose their culture because of social media trends and usage.

\subsection{What is the level of employees' readiness in the adoption of social media?}

The results clearly show that most of the employees access social media at home, i.e., after their daily work. The study found that most employees spend more than five hours 
on SM platforms daily, with WhatsApp being the platform that employees spend most of their time on.

The study found that employees are ready to adopt social media as it contributes to their personal lifestyle, promotes intercultural ideas and knowledge, provides borderless freedom in communication, and offers unlimited access to current and trending news and information 24/7. Moreover, its features are easy to use; and it provides accessible communication with friends, families, and colleagues.

\subsection{What are the impacts of culture on social media adoption?}

Furthermore, the study found that culture affects social media usage; the respondents were not sure whether cultural beliefs impact positively or negatively on social media platforms. It was found that culture impacts on what the employees can post on social media platforms, how they share post/s (information) and comments on post/s. The study also found that employees believe that their culture does not consider in the design of social media platforms. The respondents believe that their culture does not encourage them to adopt social media. The study found that social media platforms promote foreign culture and its values in the society.

\section{Conclusion}

The study demonstrated that numerous cultural elements influence employees' attitudes and behaviour towards adopting social media. The study identified different cultural factors that influence users' intentions to utilize social media platforms, as well as the level of employees' readiness to use and adopt social media platforms for personal and work-related purposes. Furthermore, the study found that different cultural factors impact on social media platforms.

The findings of the study suggest that the developers of social media platforms should consider the culture of the users, especially those of the developing countries; social media users should be guided by good moral values and their cultures while expressing themselves on social media platforms. Social media platform users should not lose their cultural values when adopting social media.

\section{Author Statement}

The authors declare that they have no conflict of interest.

\section{ORCIID}

Sikedi Ramawela (iD https://orcid.org/0000-0003-1165-4862

Joshua Ebere Chukwuere (DiD https://orcid.org/0000-0001-8366-4328

\section{References}

Abubakar, M. K., Patricia, M. N., Samuel, O. O., \& Totolo, A. (2017). Factors affecting adoption of social media by women's non-governmental organisations (WNGOs). 
International Journal of Library and Information Science, 9(9), 96-106.

Andzulis, J. M., Panagopoulos, N. G., \& Rapp, A. (2012). A review of social media and implications for the sales process. Journal of Personal Selling \& Sales Management, 32(3), 305-316.

Beger, G., \& Sinha, A. (2012). South Africa mobile generation: Study on South Africa young people on mobiles. UNICEF. Retrieved from https://www.unicef.org/southafrica/media/1041/file/South-African-mobilegeneration-2012.pdf

Boyd, D. M., \& Ellison, N. B. (2008). Social network sites: Definition, history, and scholarship. Journal of Computer-Mediated Communication, 13, 210-230.

Chukwuere, J. E., Mavetera, N., \& Mnkandla, E. (2016). An empirical study on the success factors to consider in developing e-Learning Systems: A learner-oriented system. Asian Journal of Information Technology, 15(16), 3087-3102.

Chukwuere, J. E., Mavetera, N., \& Mnkandla, E. (2017). Student's perception on cultureoriented e-learning system: An empirical study. In F. Altinay (Ed.), Open and Equal Access for Learning in School Management (pp. 145-161). IntechOpen.

Cilliers, L., Chinyamurindi, W. T., \& Viljoen, K. (2017). Factors influencing the intention to use social media for work-related purposes at a South African higher education institution. SA Journal of Human Resource Management, 15(1), 1-8.

Edosomwan, S., Prakasan, S. K., Kouame, D., Watson, J., \& Seymour, T. (2011). The history of social media and its impact on business. Journal of Applied Management and Entrepreneurship, 16(3), 79-91.

Fin24. (2017). Social media deepens its hold on SA - All the stats. Retrieved from https://www.fin24.com/Tech/News/social-media-deepens-its-hold-on-sa-all-the-stats20170920

Gökçe, K. G., \& Dogerlioglu, O. (2019). "Bring your own device" policies: Perspectives of both employees and organizations. Knowledge Management \& E-Learning, 11(2), 233-246.

Haddud, A., Dugger, J. C., \& Gill, P. (2016). Exploring the impact of internal social media usage on employee engagement. Journal Social Media for Organizations, 3(1), $1-22$.

Jami Pour, M., Matin, H. Z., Yazdani, H. R., \& Kouchak Zadeh, Z. (2019). A comprehensive investigation of the critical factors influencing knowledge management strategic alignment. Knowledge Management \& E-Learning, 11(2), 215232.

Joshua, C. E., Nehemiah, M., \& Ernest, M. (2015). A conceptual culture-oriented elearning system development framework (e-LSDF): A case of higher education institutions in South Africa. International Journal of Trade, Economics and Finance, 6(5), 259-265.

Kaitlin, C. (2010). Social media changing: Social interactions. Student Journal of Media Literacy Education, 1(1), 11-11.

Kim, Y., Sohn, D., \& Choi, S. M. (2011). Cultural difference in motivations for using social network sites: A comparative study of American and Korean college students. Computers in Human Behavior, 27(1), 365-372.

Kumar, N. S., \& Dinakaran, M. (2019). Semantic based entity retrieval and disambiguation system for Twitter streams. Knowledge Management \& E-Learning, 11(2), 262-280.

Lekhanya, L. M. (2013). Cultural influence on the diffusion and adoption of social media technologies by entrepreneurs in rural South Africa. International Business \& Economics Research Journal, 12(12), 1563-1574.

Leonardi, P. M., Huysman, M., \& Steinfield, C. (2013). Enterprise social media: 
Definition, history, and prospects for the study of social technologies in organizations. Journal of Computer-Mediated Communication, 19(1), 1-19.

Malik, S., Nawaz, F., Shujahat, M., Kianto, A., Hussain, S., \& Ali, M. (2019). The determinants of the online banking adoption behavior by the theory of trying in developing countries: The case of Pakistani banks. Knowledge Management \& ELearning, 11(2), 247-261.

Muijs, D. (2010). Doing quantitative research in education with SPSS. Thousand Oaks, CA: Sage Publications.

Mzekandaba, S. (2016). SA's Internet user numbers surge. ITWeb. Retrieved from https://www.itweb.co.za/content/DVgZeyvJbOQvdjX9

Mzekandaba, S. (2017). Number of SA Internet users ticks up. ITWeb. Retrieved from https://www.itweb.co.za/content/z5yONPvEeyvXWrba

Panjaburee, P., \& Srisawasdi, N. (2018). The opportunities and challenges of mobile and ubiquitous learning for future schools: A context of Thailand. Knowledge Management \& E-Learning, 10(4), 485-506.

Parveen, F., Jaafar, N. I., \& Ainin, S. (2015). Social media usage and organizational performance: Reflections of Malaysian social media managers. Telematics and Informatics, 32(1), 67-78.

Pereira, S., Pereira, L., \& Pinto, M. (2011). Internet and social networks: Caught up in the web. Retrieved from http://www.lasics.uminho.pt/edumedia/wpcontent/uploads/2012/01/Social-Networks-en.pdf

Pimmer, C., Lee, A., \& Mwaikambo, L. (2018). Mobile instant messaging: New knowledge tools in global health? Knowledge Management \& E-Learning, 10(3), 334-349.

Pineda, R. G. (2014). Technology in culture: A theoretical discourse on convergence in human-technology interaction. Jyväskylä Studies in Computing, 191.

Ractham, V. V., \& Srisamran, P. (2018). Effects of knowledge articulation and selfreflection on team performance. Knowledge Management \& E-Learning, 10(2), 177195.

Reneau, M. (2013). Teaching nurses sight unseen: Comparing the cultural competency of online and on-campus BSN faculty. Journal of Transcultural Nursing, 24(1), 78-85.

Shezi, L. (2016). SA's 26.8 million internet users spend almost three hours a day on social media. Retrieved from https://www.htxt.co.za/2016/04/29/the-stuff-southafrica-26-8-mil-internet-users-spend-most-their-time-doing-online/

Shezi, L. (2017). Number of South Africans with access to Internet grows to $60 \%$. Retrieved from https://www.htxt.co.za/2017/05/31/number-of-south-africans-withaccess-to-internet-grows-to-60/

Singh, T. P., \& Sinha, R. (2017). The impact of social media on business growth and performance in India. International Journal of Research in Management \& Business Studies, 4(Slp. 1), 36-40. Retrieved from http://ijrmbs.com/vol4issue1SPL1/tinap.pdf

Singla, M. L., \& Durga, A., (2015). How social media gives you competitive advantage. Indian Journal of Science and Technology, 8(S4), 90-95.

Spencer-Oatey, H. (2012). What is culture? A compilation of quotations. GlobalPAD Core Concepts.

Vithayathil, J. Dadgar, M., \& Osiri, J. K. (2020). Does social media use at work lower productivity? International Journal of Information Technology and Management, 19(1), 47-67.

Walliman, N. (2017). Research methods: The basics. New York, NY: Routledge.

Waters, R. D., \& Lo, K. D. (2012). Exploring the impact of culture in the social media sphere: A content analysis of nonprofit organizations' use of Facebook. Journal of Intercultural Communication Research, 41(3), 297-319. 